\title{
E-BRIEF
}

November 28, 2014

ECONOMIC GROWTH AND INNOVATION

\section{Measuring Innovation in Canada: The Tale Told by Patent Applications}

by

Robbie Brydon, Nicholas Chesterley, Benjamin Dachis and Aaron Jacobs

- Patent applications are a good measure of the innovative spirit in a country. Patents reward the innovation and creativity that drive economic growth. Patents provide their holders the near exclusive right to benefit from an invention, for a set amount of time, in exchange for disclosing public information about the underlying innovation.

- Our Canadian patent data shed new light on domestic "value added" by sector, and show that Canadian innovative output - as measured by domestic patent applications - is high in utilities, construction and computers and electronics, relative to other sectors. However, the pharmaceuticals and medical equipment sector has a low share of Canadian inventors applying for patents for the Canadian market.

- Across Canada, Alberta and Ontario consistently outperform national averages in domestic patent applications per capita, while the Atlantic Provinces are dramatically below average; all provinces have seen a fall in patent application rates in the last decade.

Innovation is often viewed as a talisman for economic growth. Innovation brings new products that can improve quality of life. Innovation can drive productivity and economic prosperity. But where is the innovative spirit strongest in Canada? In this E-Brief we examine which provinces and sectors have seen the most domestically applied innovation, by looking at trends in patenting by Canadians

The authors wish to thank reviewers who commented on earlier versions of this paper. The authors retain responsibility for any remaining errors. 
for use in the Canadian market. This presents a new way of studying Canadian innovation that can capture not only the inputs of the innovation process, such as research and development spending, but the outputs applied in Canada.

This E-Brief employs a new database on patent applications in Canada to study which sectors and which provinces are relatively strong in the domestic application of innovation, and which are relatively weak, to better understand what policy environments encourage and support innovation.

We find residents of Alberta and Ontario, and Canadian inventors in the utilities, construction and computers and electronics sectors produce a disproportionately large share of patents for the Canadian market. By contrast, residents of the Atlantic Provinces and Canadian inventors in the pharmaceuticals and medical equipment sectors are not producing a large share of patents for use in Canada. Comparing these areas and sectors provides a promising source of lessons for Canadian policy.

\section{Innovation and Patents}

Patents provide a patent holder the right, granted by government, to limit others' use or sale of the patent holder's invention in Canada. In exchange, inventors are required to disclose some details of their inventions to the public, so that society as a whole may better benefit from them. The system is intended to reward and stimulate innovation, while providing a way for others to share in its benefits.

To acquire a patent, applicants must file with a patent office, either in their own country or abroad, an application describing the invention. Patents must meet the standards of novelty, non-obviousness, and usefulness. The rights granted are limited in time and to the country of the office that issued it, but it is possible to apply to multiple offices simultaneously, or to use an application at one office to get priority in applications elsewhere. ${ }^{1}$

\section{Patents as a Measure of Innovation}

Innovation is in many ways intangible, and for that reason is difficult to measure. Technological innovation is a key driver of living standards and prosperity, and is an important focus of policy, for example narrowly targeted interventions like tax credits for research and development (R\&D), as well as broader policies like reducing tariffs on high-tech goods. Patents provide one possible measure of the output of innovation, and surveys have found they provide insight into the innovation and commercialization process (Griliches et al. 1987; Archibugi and Pianta 1996). Other common measures include R\&D spending, the number of R\&D personnel, and innovation surveys.

Patents, however, have several advantages as a measure of innovation. Most obviously, they represent a direct outcome of the research process, rather than an input, like R\&D spending. They also provide considerable information on the invention, allowing better understanding of the quantity and quality of innovation, and potentially its allocation by location or sector, over a significant period of time.

1 The Paris Convention of 1883 specifies that after a patent application is filed in an initial country, applicants have 12 months to file applications elsewhere: if they do so, those applications are treated as if they were filed on the same date as the original application. Alternatively, applicants can use the Patent Cooperation Treaty Procedure, which allows applicants to delay filing national applications until as long as the thirtieth month in exchange for using a unified filing procedure (OECD 2009). 
The dominant trend in patenting has been increasing globalization, as patent markets and markets generally become more integrated. This is especially true for Canada, where 82 percent of patent applications by Canadian inventors are made abroad (WIPO 2013). Recently, however, many commentators have shown concern about the low level of Canadian innovation, and particularly Canadian patenting, with several rankings putting Canada at or near the bottom of the Organisation for Economic Co-operation and Development (Conference Board of Canada 2013; Cornell University et al. 2013).

Patents also have some limitations as a measure of innovation. In particular, many patents are acquired and never used, whether because the firm lacks the downstream capabilities to exploit them or because firms purchased them with the intention of blocking competitors' access to them; some surveys suggest this may apply to as many as 40 percent of patents (PATVAL 2005). Some inventions are never patented, as some companies and industries prefer to rely on maintaining trade secrets or other strategies. And even those patents that are used tend to vary widely in value, with a small fraction of the total having enormous value to their owners, while the majority are worthless or impose a social cost by impeding innovation elsewhere (Galasso and Schankerman 2014). The number of patent applications therefore provides an important, but by no means final, measure of innovation.

\section{Canadian Patent Data}

To better understand these issues and look at the details of patenting within Canada, rather than broad national or international trends, the C.D. Howe Institute has constructed a database of patent applications to the Canadian Intellectual Property Office (CIPO) for the period 1980 to 2013 (CIPO 2014). CIPO issues patents that expire 20 years after the initial application was filed, and relies on the criteria of novelty, non-obviousness, and practical utility to judge what is acceptable. ${ }^{2}$

Our database of over 1 million patent applications includes a variety of information on each application. It includes technical field of invention, year the patent was applied for, location and identity of inventor(s), location and identity of applicant(s), whether the application was originally filed in another country, when and to whom the patent has been sold, and its current owner. ${ }^{3}$

Because the database covers all patent applications filed at the Canadian Intellectual Property Office, we are able to focus on innovations in Canada and abroad that are intended for use in Canada. The approach, unlike measures of research inputs or measures of Canadian applications abroad, enables us to study innovation with intended application and potential commercialization in Canada. ${ }^{4}$

2 The range of acceptable subject matter for patents is narrower in Canada than in many other jurisdictions. In particular, unlike the United States Patent and Trademark Office, CIPO does not grant patents that consist only of a theorem or abstract principle. It requires a tangible embodiment of the idea for the patent to be issued. The Supreme Court has also ruled against patentability for higher life forms such as animals and some types of plants. More generally, patent offices and particularly the United States Patent and Trademark Office have come under considerable criticism for granting patents that are obvious or otherwise unjustified.

3 Our database lacks, however, information on patent citations, preventing us from tracking how patents interact.

4 The total number of applications to the Canadian office is also publicly available from the World Intellectual Property Office (WIPO). After 1989, our data closely matches that of WIPO; before then, the levels diverge somewhat. This may be due to methodological changes from the 1989 Patent Act. 
Over the period from 1990 to 2007, the aggregate number of patent applications increased from about 25,000 per year to over 41,000, with slightly lower numbers since then (Figure 1). Manufacturing industries dominate applications for Canadian patents. The two largest subsectors leading patent activity are pharmaceutical and medical equipment manufacturing, and computer and electronic product manufacturing. Note that we group the remaining manufacturing subsectors (which are quite diverse) under "other manufacturing." The construction and utilities industries make up a relatively low share of aggregate patent activity, although as we discuss below, they out-perform in terms of the presence of Canadian inventors.

We focus on a single measure, patent applications to CIPO, as an indicator of the level of innovation intended for use in Canada and of the relative performance of provinces and industries (Box 1 contains a more detailed discussion of our methodology).

We also drill down to identify Canadian inventors. Since 1990, the average share of patent applications in Canada made by Canadian residents has increased. The increase has been dramatic in the computer and electronic product sector, and there has been a steady increase in the mining, quarrying and oil and gas extraction industry (Figure 2). Canadian involvement in construction and utilities patents, meanwhile, seems to have peaked in the early 2000s, while in the pharmaceutical and medical device sector involvement seems to have always been low.

\section{The Provincial Innovation Index}

Where do these Canadian inventors live? To find out we look at the number of patent applications by province of their first-listed inventor, relative to population measured in millions (Figure 3). The provinces vary significantly in their patent application activity, as might be expected given their relative differences in population and economic activity.

On a per capita basis, Ontario and Alberta are top performers, while the Atlantic Provinces trail the rest of Canada. Alberta outperforms both the national average and the other Western provinces, suggesting that it is a hub for patenting activity. From a high in the early 2000 s - which was nevertheless a low number by international standards (Cornell University et al. 2013) - all provinces have shown a decline in patent applications per capita.

\section{The Sectoral Innovation Index}

In what sectors do these inventors work? Patent applications vary widely by sector. The raw number of patent applications per year is a reflection of the industrial structure of the economy and those parts of it that tend to show the most patenting activity.

The number of patent applications to CIPO per worker does not tell us what kinds of innovation Canadians are best at putting to use in the domestic market. The degree to which different sectors make use of patents - as opposed to trade secrets or other intellectual property mechanisms - varies greatly. To get a sense of the relative presence of Canadians, we construct a sectoral innovation index that measures the participation of at least one inventor living in Canada in patent applications for a given sector relative to the average (see Box 1 for details). This measure shows in which sectors Canadian inventors are outperforming compared to other sectors.

5 See Appendix A for a description of the process of matching patents to industry classifications. 


\section{Figure 1: Aggregate Patent Applications, by Industry}

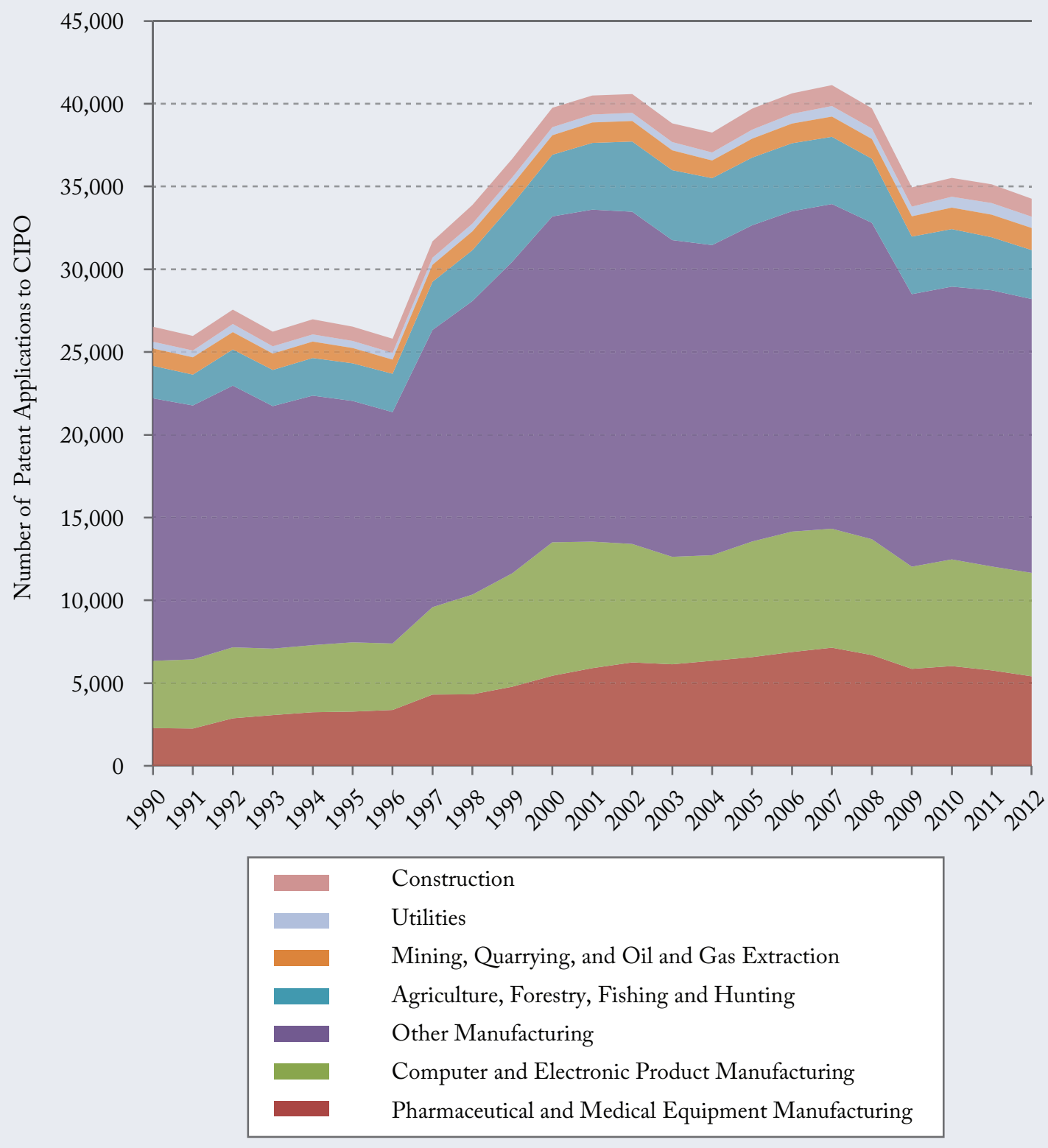

Source: Authors' calculations from CIPO and Statistics Canada data. 


\section{Box 1: What We Are Measuring}

Our analysis uses data on patents from the Canadian Intellectual Property Office for information on Canadian patents and Statistics Canada CANSIM (Table 051-0001) for population data. Our data cover all applications to the Canadian Intellectual Property Office from 1980-2013. Before 1990, it includes only granted patents, while after 1990, it includes all patent applications, due to a methodological change at CIPO. Importantly, this covers all applications made to the Canadian office, rather than all applications made by Canadians: our focus is on innovation intended for use in Canada.

At the provincial level, per capita patent application rates are calculated by dividing the number of patents with a first-listed inventor from each province by the population of that province. We exclude patents for which the address of the inventor is not listed by CIPO, but our focus on shares means that if such omissions are random, this will not affect the analysis. It is not clear if there is a systematic bias in the omission of addresses. We use the first-listed inventor to assign a patent to a province for convenience: there is no significance to the order of inventors on a patent, and it is determined solely by the inventors themselves. In addition, in some cases CIPO may not preserve the original order of inventors or applications.

Our sector innovation indices are calculated as:

$$
\text { Innovation Index }{ }_{i, y}=\left(P_{i, y, n} / P_{\bar{i}, y, n}\right) /\left(P_{i, y, \bar{n}} / P_{\bar{i}, y, \bar{n}}\right)
$$

where $P$ is the number of patents in industry $i$ invented by residents in country $n$ in year $y$, and $\bar{i}$ and $\bar{n}$ refer to all industries or countries. We construct the innovation index for specific Canadian industries, and so in our analysis $n$ refers to the number of patents with at least one inventor from Canada. For example, in 2012, residents of Canada applied for 1,811 patents, related to what we call other manufacturing, at the Canadian Intellectual Property Office. In total, Canadians applied for 4,059 patents at CIPO that year. Manufacturing thus generated 45 percent of Canadian residents' patent applications at CIPO. Overall, 16,541 patents related to other manufacturing were applied for at CIPO that year by residents of all countries, out of a total of 34,262 : 48 percent. The manufacturing innovation index for 2012 is therefore $0.45 / 0.48=0.92$.

We measure all patent applications, rather than restricting our analysis to granted or triadic patents, as is sometimes done. This allows us to avoid data truncation in recent years, since granting a patent is often a multiyear process, but means we do not discriminate among patent applications on the basis of quality or commercial value, or whether they are ultimately approved.

A score of one on this index implies that Canadians file for Canadian patents in that industry at the same rate as Canadians do for all industries, on average.

On this index, the construction and utilities sectors consistently over-perform, representing significant areas of Canadian innovation applied in the Canadian market (Figure 4). ${ }^{6}$ In recent years, Canadians have dramatically

6 For details on how the sector allocation is done, see Appendix. 


\section{Figure 2: Share of Patent Applications with At Least One Inventor in Canada,}

\section{Selected Industries}

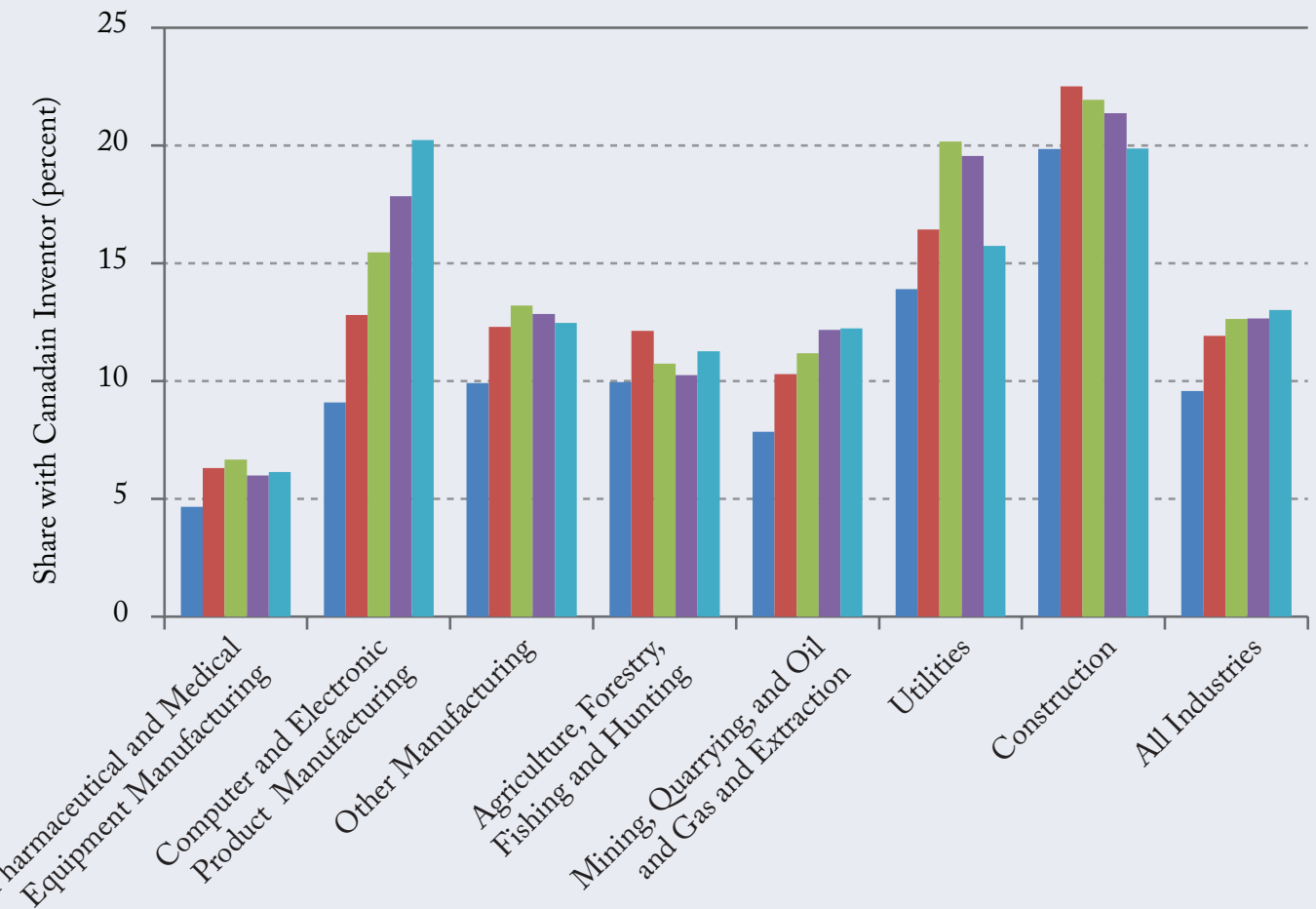

Source: Authors' calculations from CIPO and Statistics Canada data.

increased their activity with respect to computer and electronic product patents, pushing other industries downward in comparison. Manufacturing sectors, other than for medical or electronic usage, have remained relatively close to the average. The mining, quarrying and oil and gas extraction sector has also stayed close to the national average, although with steady improvement over time.

In contrast, the patent-reliant pharmaceutical and medical devices manufacturing sector shows a relatively weak Canadian presence. It seems plausible that its poor performance is due in large part to significant innovation abroad. Though pharmaceutical products have sometimes been seen as a Canadian innovative strength (Council of Canadian Academies 2013), our analysis seems to indicate that when Canadians do contribute to these sectors, their contributions may be intended for international markets. 


\section{Figure 3: Average Annual Applications per Capita, by Province}

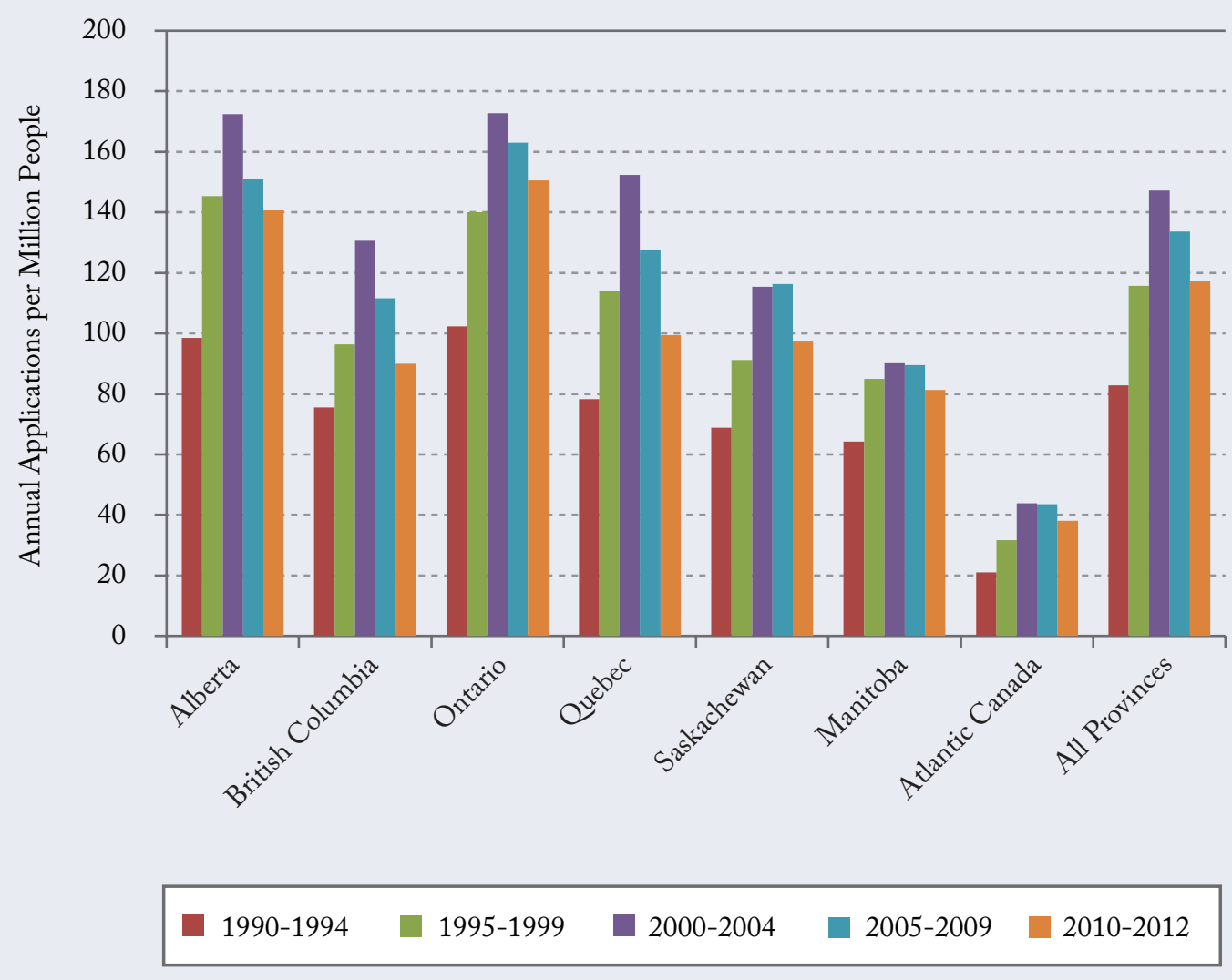

Source: Authors' calculations from CIPO and Statistics Canada data.

\section{Policy Implications}

Across the board, Canada is performing relatively weakly compared to international averages in terms of patenting activity (Conference Board of Canada 2013). This average, however, conceals both areas of strength and areas of weakness in the domestic application of research in Canada.

Provincially, Alberta stands out as a success story, with it and Ontario leading the pack in terms of patents per capita. This may in part be due to differing rates of urbanization and population density, as innovation is often best done with a surrounding peer group (Jaffe et al. 1993). All the provinces, however, have seen a decline in patent applications per capita in the last decade. In the pharmaceutical and medical device sector, Canadian inventors looking to patent in Canada are few and far between, while in the computer and electronic product sector their contributions are quickly rising. The construction and utilities sectors remain sources of disproportionate Canadian-applied innovation by Canadians. 


\section{Figure 4: Innovation Index, by Sector}

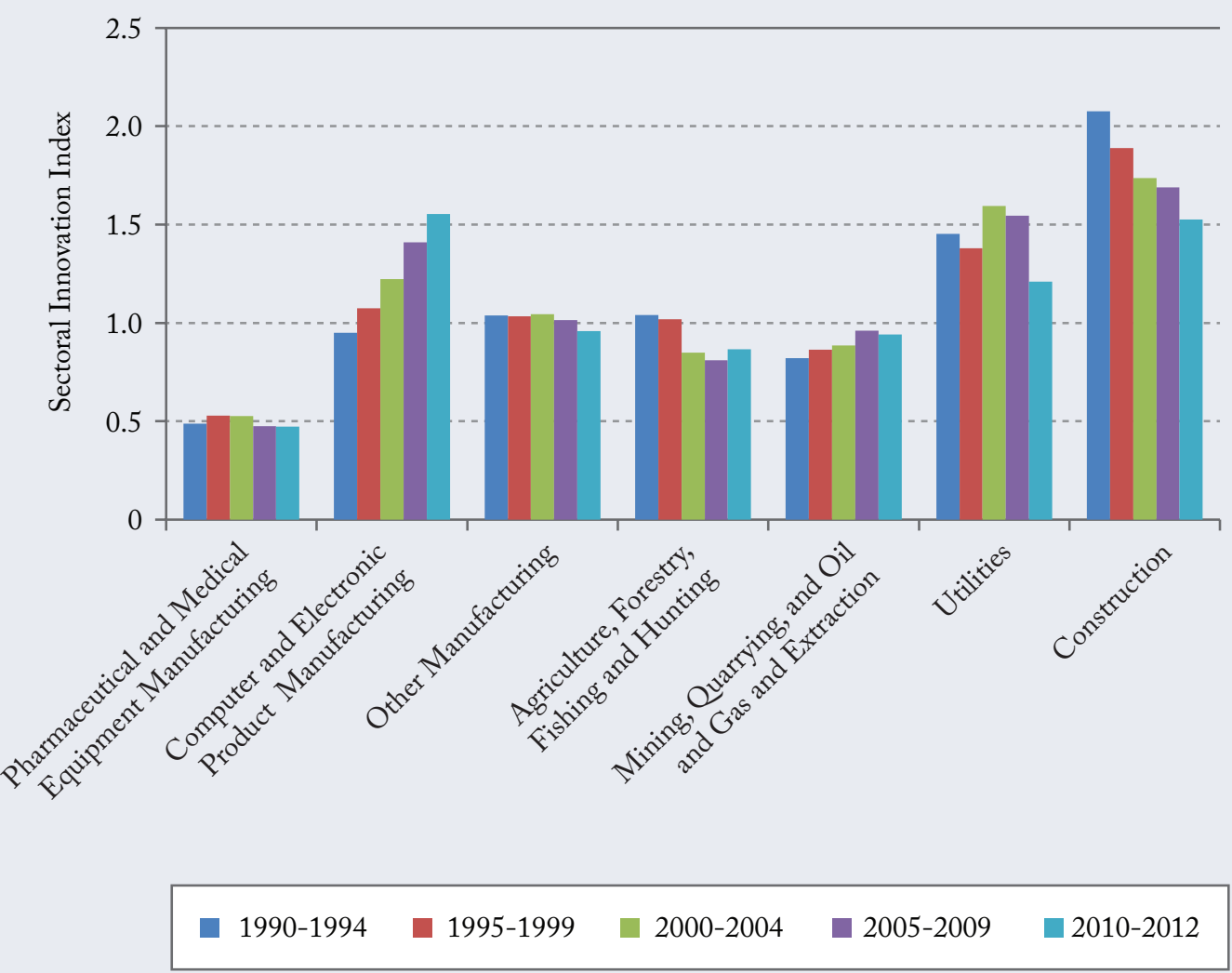

Source: Authors' calculations from CIPO and Statistics Canada data.

The above results put a new perspective on the value-added debate and show that researchers in Alberta and in the utilities and construction sector - areas that are often seen as producing little "value added" - are outperforming researchers in many other parts of the economy in applying their work to the Canadian market.

Such differences point to a number of broad policy lessons. Canadian governments have implemented a variety of policies at the provincial and federal levels to encourage innovation in Canada. The country has one of the world's most generous tax regimes for R\&D, particularly the Scientific Research and Experimental Development tax credit (Parsons 2011). There have also been calls for the revenues from intellectual property, such as patents, to enjoy a preferential tax rate, to encourage commercialization (Pantaleo et al. 2013). This policy could encourage Canadians to more energetically develop commercial applications for their innovation in Canada. Canada often performs well on measures of R\&D inputs, such as journal publications or academic citations (STIC 2013), but as measured by patent applications it appears to be struggling with the commercialization aspect of the innovation process. 
Overall, 85 percent of patents filed in Canada involve no Canadian inventors. This can bring significant benefits to Canada in the form of foreign innovation, but some studies also suggest that Canada might be better able to absorb foreign technologies in sectors with a high domestic innovation capacity (Maskus 2004).

We intend to do much more work with our patent database investigating these and related questions. In particular, questions about the background drivers of innovation as well as the effect of various policies can be studied in significantly more depth. Looking at innovation from the perspective of cities and clusters of industry can help explain spillover effects of innovation. For example, the cluster of unconventional oil and gas deposits in Alberta may create patent activity with localized applications, and localized gains from innovation.

Patents are by no means the last word on innovation, but they represent an important piece of the broader puzzle, particularly given the wide variation in patent productivity in Canada. Understanding the sector-by-sector levels of innovation as well as which provinces are innovating the most is a starting point of assessing these policies and patenting in Canada more generally, which we encourage researchers and innovators themselves to explore using our database of Canadian patents.

\section{Conclusions}

Because patents represent only an imperfect measure of innovation, research on understanding the landscape of Canadian innovation is essential. Our work identifies a few areas of success as well as failure from which Canadians might learn and improve. Given Canada's apparently poor record in patenting and innovation, Canadian policymakers should ponder whether and how to better encourage innovation and its use. 


\section{Appendix A}

To understand how patent contributions have varied across different sectors of the economy, we match our database to the North American Industry Classification System (NAICS). Patents are classified by the CIPO on the basis of the International Patent Classification System (IPC) - which identifies human necessities; performing operations and transporting; chemistry and metallurgy; textiles and paper; fixed constructions; mechanical engineering, lighting, heating, weapons, and blasting; physics; and electricity - but does not correspond to the eventual industry or industries in which the patent may one day be put to use. Performing this matching is an area of ongoing academic work.

The most recent contribution to this field is the work of Lybbert and Zolas (2012) at the World Intellectual Property Organization, who use a variety of data mining techniques to establish a weighted probability mapping of IPC codes to industry classifications, including the NAICS. We match our database to the probability weights at the four-digit 2007 NAICS codes using the tables provided by the authors based on the first listed IPC code of each patent, which is often the primary IPC code. For the 1986-2013 period, this corresponds to 867,550 weighted patent units with only 50 patents that could not be matched to an industry.

To construct the set of industries of interest that we examine in this report, we take the first two, three, or four digits of the NAICS codes, depending on the relative number of patents these industries contribute, as well as a certain amount of judgment. This is primarily out of a desire to include electronics and pharmaceutical sectors as a high-level category, despite the fact that these industries are three- and four-digit NAICS codes, respectively, while all of the others are two-digit codes. A table listing our industry classifications and their constituent NAICS codes may be found in Table A-1.

\section{Table A-1: Industry Categories, by NAICS Code}

\begin{tabular}{|l|l|}
\multicolumn{1}{|c|}{ Industry Category } & \multicolumn{1}{|c|}{ Constituent NAICS 2007 Code(s) } \\
\hline Pharmaceutical and Medical Equipment Manufacturing & 3254 and 3391 \\
\hline Computer and Electronic Product Manufacturing & 334 \\
\hline Other Manufacturing & All 31-33, excluding 334, 3254, and 3391. \\
\hline Agriculture, Forestry, Fishing and Hunting & 11 \\
\hline Mining, Quarrying, and Oil and Gas Extraction & 21 \\
\hline Utilities & 22 \\
\hline Construction & 23 \\
\hline Source: Statistics Canada. & \\
\hline
\end{tabular}




\section{References}

Archibugi, Daniele, and Mario Pianta. 1996. "Measuring technological change through patents and innovation surveys.” Technovation. 16(9). 451-68.

Bettencourt, L. M., J. Lobo, D. Helbing, C. Kühnert, and G.B. West. 2007. "Growth, innovation, scaling, and the pace of life in cities." Proceedings of the National Academy of Sciences USA, 104(17). 7301-6.

Canadian Intellectual Property Office (CIPO). 2014. Patent Database. Ottawa.

Conference Board of Canada. 2013. "Patents Index." Ottawa: The Conference Board of Canada. April.

Cornell University, INSEAD, and WIPO. 2013. The Global Innovation Index 2013: The Local Dynamics of Innovation. Geneva, Ithaca, and Fontainebleau.

Council of Canadian Academies. 2013. "The State of Industrial R\&D in Canada." Ottawa, ON: The Expert Panel on Industrial R\&D in Canada, Council of Canadian Academies.

Galasso, Alberto, and Mark Schankerman. 2014. "Patents and Cumulative Innovation: Causal Evidence from the Courts.” NBER Working Paper, No. 20269. June.

Griliches, Zvi, Ariel Pakes, and Bronwyn H. Hall. 1987. "The Value of Patents as Indicators of Inventive Activity." Economic Policy and Technical Performance, eds. P. Dasgupta and P. Stoneman, pp. 97-124. Cambridge: Cambridge University Press. October.

Jaffe, Adam, Manuel Trajtenberg, and Rebecca Henderson. 1993. "Geographic Localization of Knowledge Spillovers as Evidenced by Patent Citations.” Quarterly Journal of Economics. 108(3). 577-98.

Lybbert, Travis J. and Nikolas J. Zolas. 2012. Getting Patents and Economic Data to Speak to Each Other: An "Algorithmic Links with Probabilities" Approach for Joint Analyses of Patenting and Economic Activity. WIPO Economics \& Statistics Series. World Intellectual Property Organization.

Maskus, Keith E. 2004. Encouraging International Technology Transfer. Geneva: International Center for Trade and Sustainable Development.

OECD. 2009. OECD Patent Statistics Manual. Paris. February.

Pantaleo, Nick, Finn Poschmann, and Scott Wilkie. 2013. Improving the Tax Treatment of Intellectual Property Income in Canada. Commentary 379. Toronto: C.D. Howe Institute. April.

PATVAL. 2005. The Value of European Patents: Evidence from a Survey of European Inventors. Final Report of the PATVAL EU Project. January.

Parsons, Mark. 2011. Rewarding Innovation: Improving Federal Tax Support for Business RED in Canada. Commentary 334. Toronto: C.D. Howe Institute. September. 
Science, Technology and Innovation Council. 2013. State of the Nation 2012 - Canada's Science, Technology, and Innovation Systems. Ottawa: STIC.

World Intellectual Property Office. 2013 World Intellectual Property Indicators. Geneva: World Intellectual Property Office.

This E-Brief is a publication of the C.D. Howe Institute.

Robbie Brydon is Research and Evaluation Analyst, Homeward Trust, Edmonton.

Nicholas Chesterley is Clarendon Scholar, SSHRC Doctoral Fellow and PhD Candidate in Economics, University of Oxford.

Benjamin Dachis is a Senior Policy Analyst, C.D. Howe Institute.

Aaron Jacobs is a Research Intern, C.D. Howe Institute.

This E-Brief is available at www.cdhowe.org.

Permission is granted to reprint this text if the content is not altered and proper attribution is provided. 